\title{
Fabricating an Air-Retaining Surface on Outer Surface of Wetsuit by In-Situ Synthesis of Silica Nanoparticles
}

\section{MANOUCHEHR RAD ${ }^{1 *}$, RAMIN KHAJAVI' ${ }^{2}$ MINA ABBASIPOUR ${ }^{3}$, SIAMAK NAZEMI ${ }^{4}$ and AMIRHOSEIN BERENDJCHI ${ }^{3}$}

\author{
${ }^{1 * D e p a r t m e n t ~ o f ~ M e c h a n i c a l ~ E n g i n e e r i n g, ~ S o u t h ~ T e h r a n ~ B r a n c h, ~ I s l a m i c ~}$ \\ Azad University, Tehran, Iran. \\ ${ }^{2 *}$ Department of Textile and Polymer Engineering, South Tehran Branch, Islamic \\ Azad university, Tehran, Iran. \\ ${ }^{3}$ Department of Textile Engineering, Science and Research Branch, Islamic \\ Azad University, Tehran, Iran. \\ ${ }^{4}$ Department of Textile Engineering, Yazd Branch, Islamic \\ Azad University, Yazd, Iran. \\ *Corresponding author E-mail: manouchehr.raad@gmail.com
}

http://dx.doi.org/10.13005/ojc/330313

(Received: March 16, 2017; Accepted: April 14, 2017)

\begin{abstract}
In this study, it was aimed to fabricate a super hydrophobic layer as an air-retaining surface on a commercial wet suit to reduce the drag force. Silica nanoparticles (SiNPs) were synthesized in situ on the outer surface of a wet suit through sol-gel method and then they were treated with hydrolyzed n-octyltriethoxysilane (OTES). Scanning electron microscopy (SEM) and atomic-force microscopy (AFM) images showed a uniform formed coating of SiNPs on the surface of wet suit. The values of Static water-contact angle (SWC) and water-shedding angle (WSA) for hydrolyzed samples were $153^{\circ}$ (for a $10 \mu \mathrm{L}$ water droplet) and $34^{\circ}$ (for a $15 \mu \mathrm{L}$ water droplet) respectively. Attributed to the desired formed air film, the wind tunnel test results showed drag reduction for coated wet suit. The introduced product showed high potent for long distance swimming and triathlon.
\end{abstract}

Keywords: Wet suit, Drag force, Air retaining surface, Super hydrophobic surface, Air film

\section{INTRODUCTION}

Drag or hydrodynamic resistance plays an important role in swimming performance and in general for every moving object submerged in water. Over $90 \%$ of the swimmer's power output is spent overcoming hydrodynamic drag ${ }^{1,2}$. There are three different types of drag: pressure, wave, and friction. Pressure or form drag is the energy required to move fluid in front of an object in the flow. The energy required for creating velocity gradients in the fluid layer to move the object is named drag ${ }^{3}$. The speed 
of swimmers depends on hydrodynamic drag force. To achieve higher speed, the hydrodynamic drag force should be reduced for forward motion. Several studies have investigated the effect of swimsuits on hydrodynamic drag ${ }^{4-7}$.

One way to reduce drag is to use a layer of air bubbles on the surface of the object. The air water interface reduces the hydrodynamic force. In this field, superhydrophobe surfaces play an important role, as they are capable of trapping air pockets due to their roughness and their low surface energy because of micro and nanoscale features. A superhydrophobic substrateis defined as a surface with low wett ability and with a contact angle (CA) greater than $150^{\circ}$. Many fabricated superhydrophobic surfaces are based on mimicking biological airretaining plants such as the floating ferns Salvinia and the back swimmer Notonecta. The attempt to reduce hydrodynamic drag was originally inspired by the unique properties of fast-swimming shark skin. A layer of air trapped on the surface of the object leads to slip which exhibits drag reduction. This slip reduces drag at higher Reynolds numbers in both laminar and turbulent regimes ${ }^{8,9}$. Different studies presented the drag reduction of laminar flow through microchannels by using hydrophobic surfaces ${ }^{10-12}$. For example, Henoch et al. (2006) ${ }^{13}$ demonstrated that superhydrophobic surfaces reduce the drag force at velocities up to $1.4 \mathrm{~m} / \mathrm{s}$.

Up to now many methods have been presented for fabricating such surfaces on different substrates, ${ }^{14-17}$ including lithography, chemical vapour deposition, a sol-gel process, electrochemical deposition, layer-by-layer assembly, and etching ${ }^{18-22}$.A sol-gel process is a wet chemical procedure that makes it simple to synthesize metal-oxide nanoparticles. In this process, metal alkoxide, which is used as a precursor, is dissolved in water or alcohol to form a colloidal solution (sol). The gel is formed through hydrolyses and then condensation of the colloidal solution. The sol-gel method is economical-it, as a low-temperature technique, affords good control of the obtained products. Typically, siliconalkoxide groups, such as tetraethoxysilane $\mathrm{Si}\left(\mathrm{OC}_{2} \mathrm{H}_{5}\right)_{4}$ (TEOS), have been used as Si precursors $23-29$.

Swimwear can be divided into two categories: wet suits and dry suits. Both types of diving suits protect divers from water and the elements. Dry suits are mostly used for warm water. Wet suits show some benefits over dry suits including being relatively inexpensive and easily wearable. It is usually made of foamed neoprene coated sometimes with a fabric such as PET. It is used by surfers, divers, windsurfers, canoeists, and others engaged in water sports, providing thermal insulation, abrasion resistance, and buoyancy. Bubbles of gas in the surface of wet suits lead to drag reduction as well as heat conduction. They make the wet suit with a low density and provide buoyancy in water. Its drag or hydrodynamic resistance depends on the behaviour of the outer surface.

By considering different literatures, there is no study to reduce the drag of wet suits by superhydrophobic coating to ease body movement. So in this study, it was intended to convert the outer surface of the wet suit into an air-retaining surface by fabricating a superhydrophobic surface on it and thereby reducing the hydrodynamic drag. SiNPs were synthesized in-situ on a commercial wetsuit by solgel method. They were treated with a hydrolyzedalkyl silane solution. Samples were characterized by scanning electron microscopy (SEM), atomicforce microscopy (AFM), and energy-dispersive spectroscopy (EDS). The superhydrophobic effect was investigated by measuring the SWC, WSA, and surface energy. Finally, the hydrodynamic drag of samples determined in a wind tunnel and compared with untreated samples.

\section{MATERIALS AND METHODS}

A commercial wet suit (including PET fabric coated with neoprene) provided by Mares Company (Rapallo, Italy). Tetra ethyl ortho silicate(TEOS), n-octyltriethoxysilane (OTES), ammonium hydroxide (25\%), ethanol (96\%) and hydrochloric acid were purchased from Merck.

\section{Procedures}

$\mathrm{SiO}_{2}$ nanoparticles were synthesized in accordance with the Stöber method[30]. Briefly, ethanol $(25 \mathrm{ml})$, ammonium hydroxide $(1 \mathrm{ml})$, distilled water $(3.6 \mathrm{ml})$, and TEOS $(11.5 \mathrm{ml})$ were stirred for $2 \mathrm{~h}$ at room temperature to prepare the sol-gel solution. Wet suit samples $\left(5 \mathrm{~cm}^{2}\right)$ were immersed in the prepared solution at $30^{\circ} \mathrm{C}$ for $5 \mathrm{~min}$, dried at $60^{\circ} \mathrm{C}$, and then cured at $160^{\circ} \mathrm{C}$ for $5 \mathrm{~min}$. OTES $(17$ $\mathrm{ml}$ ) and hydrochloric acid $(0.05 \mathrm{M}, 4.2 \mathrm{ml})$ were mixed and stirred for $24 \mathrm{~h}$ at room temperature. Samples 
were immersed in hydrolyzed and diluted OTES (with $4 \% \mathrm{wt} / \mathrm{wt}$ ethanol) for $4 \mathrm{~h}$ at room temperature. The samples treated with hydrolyzed OTES were cured at $120{ }^{\circ} \mathrm{C}$ for $1 \mathrm{~h}^{30}$.

\section{Characterization}

The morphology of samples was observed using SEM(XL30, Philips, Royal Philips Electronics, Amsterdam, Netherlands), and their surface roughness was measured via AFM (Danish Micro Engineering A/S, Copenhagen, Denmark) in tapping mode. Fourier Transform Infrared (FTIR) spectra were measured by FTIR spectrophotometer (Bruker Optics) in ATR mode (Germany). The SWC was measured using a contact-angle measurement device (Data physics OCA, Germany). A $10 \mu \mathrm{l}$ droplet of deionized water was placed at each of the five different positions on the sample surfaces, and the angle of each drop on the sample was determined. The SWC values and surface energy of the samples were reported based on an average of three measurements (Dataphysics OCA, Germany). The WSAs of the various samples were measured following the method of Zimmermann et al. ${ }^{31}$.The droplet $(15 \mu \mathrm{l})$ was released at a height of $1 \mathrm{~cm}$, and the minimum angle at which the droplet started to roll off the surface was then determined. Each test was repeated three times.

The drag reduction was studied by wind tunnel. The experiments were performed in a closed-circuit wind tunnel of $45 \times 45 \mathrm{~cm}^{2}$ test section with a length of $120 \mathrm{~cm}$ at Amir kabir University of Technology. The experimental setup is shown in Figure 1. A cylinder of $110 \mathrm{~mm}$ diameter and 200 $\mathrm{mm}$ length was covered with fabric and stood at an angle of $90^{\circ}$. The wind tunnel was run at a velocity of $15 \mathrm{~m} / \mathrm{s}$.

\section{RESULTS AND DISCUSSION}

The process for synthesizing SiNPs is shown in Figure 2. TEOS was hydrolyzed and silica nanoparticles nucleates were obtained by Si-O-Si bonding during the condensation reaction; thereby, the sol-gel solution was obtained. The surface of the solvent was evaporated after the sample treated with the sol solution had been dried and cured. In this step, the treated sample was still hydrophilic due to the presence of hydroxyl groups in the silicon nanostructures. The hydrophobic surface was then obtained by the interaction of hydrolyzed OTES with silanol groups (Figure 2) ${ }^{31}$.

The surface morphologies of the untreated and OTES-TEOS- treated samples were investigated by electron microscopy. The SEM images of the samples are shown in Figure 3.As shown in the Figure 3a,the untreated sample had a smooth structure, whereas the treated sample with SiNPs had a rough surface. An SEM survey of 20 synthesized $\mathrm{SiO}_{2}$ nanoparticles showed that the fabricated nanoparticles had an average size of $76 \mathrm{~nm}$.

The AFM images of the untreated and OTES-TEOS-treated wet suit surface are provided in Figure 4. It is obvious that the untreated sample is smooth (Figure 4a), while the treated sample has a rough surface (Figure $4 b$ ). The root-mean-

Upper wall of wind tunnel

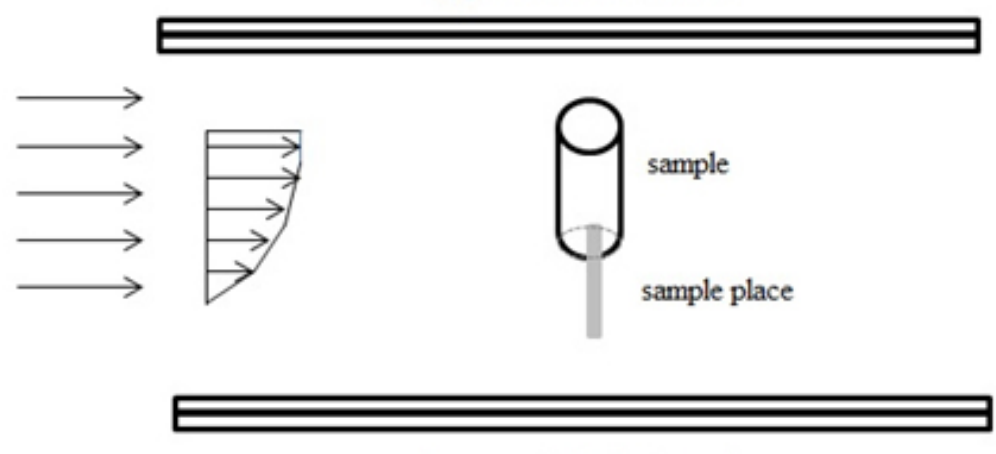

bottom wall of wind tunnel

Fig. 1: Schematic of wind Tunnel 
square (RMS) roughness of the wet suit was also measured by AFM-software. The untreated sample had an RMS roughness of $46 \pm 0.05 \mathrm{~nm}$, whereas the treated wet suit samples with OTES-TEOS had an RMS roughness of $80 \pm 0.1 \mathrm{~nm}$.
The surface elemental analysis of the treated wet suit was carried by EDS (Table 1). The results show just an Au peak for the untreated sample, while there is a Si value for both TEOS and TEOS-OTES samples. As expected, the amount of Si

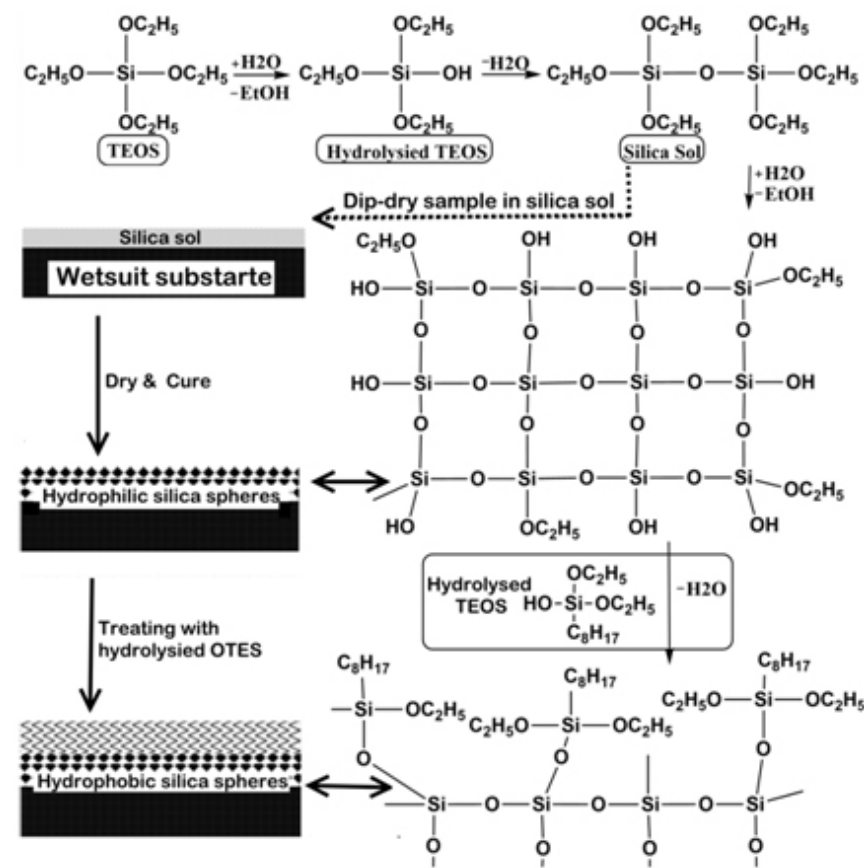

Fig. 2: Schematic and chemical reactions for the fabrication of a superhydrophoic SINPs on the surface of a wetsuit

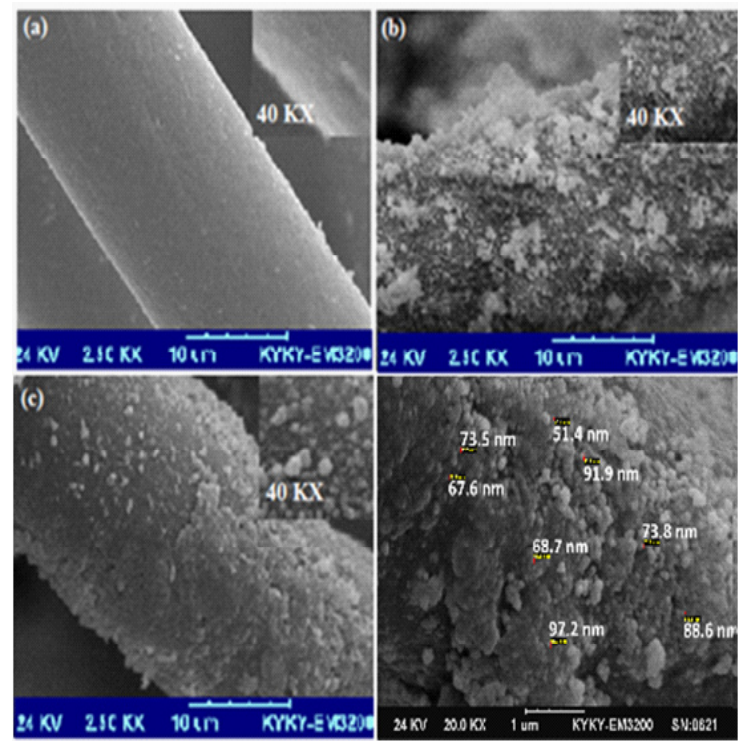

Fig. 3: SEM images of (a) Untreated, (b) TEOS and (c) OTES"TEOS coated samples, and (d) Particles size of $\mathrm{SiO}_{2}$ nanoparticles for OTES"TEOS coated samples. Images on the right are at higher magnification 
increased from $65.43 \%$ to $92.99 \%$ for TEOS-OTES samples. Therefore, post treatment of TEOS samples with OTES result in to more deposition of Si on the surface.

To consider the characteristic peaks of silicon and its oxide form, the FTIR transmittance spectra of different samples are shown in Figure 5 in the range of $750 \mathrm{~cm}^{-1}$ to $1250 \mathrm{~cm}^{-1}$. The characteristic bands at $800 \mathrm{~cm}^{-1}$ and $900 \mathrm{~cm}^{-1}$ are attributed to the stretching of $\mathrm{SiO}$ bending and $\mathrm{SiOH}$ bonds respectively. The characteristic bond at $1090 \mathrm{~cm}^{-1}$ is related to the stretching of SiOSi. It is seen that there are no Si characteristic bonds for

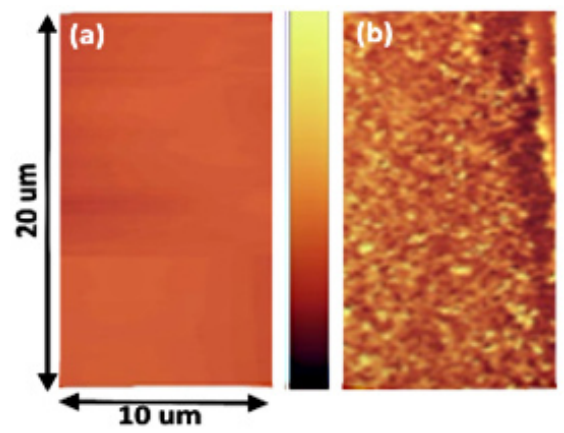

Fig. 4: AFM images of (a) Untreated (b) OTESTEOS-treated wetsuit's samples

Table 1. Energy Dispersive X-ray Spectroscopy results of a) pristine polyester b) TEOS-treated sample c) OTES-TEOS-treated sample

\begin{tabular}{lccc}
\hline \multirow{2}{*}{$\begin{array}{l}\text { with } \\
\text { Element }\end{array}$} & \multicolumn{3}{c}{ Sample Kind / treated sample } \\
\cline { 2 - 4 } & $\begin{array}{c}\text { Pristine } \\
(\%)\end{array}$ & $\begin{array}{c}\text { TEOS } \\
(\%)\end{array}$ & $\begin{array}{c}\text { TEOS-OTES } \\
(\%)\end{array}$ \\
\hline $\mathrm{Si}$ & - & 65.43 & 92.99 \\
$\mathrm{Au}$ & $100 \%$ & 34.57 & 7.01 \\
Total & 100 & 100 & 100 \\
\hline
\end{tabular}

untreated samples. On the other hand, TEOS-OTES sample has weaker $\mathrm{SiOH}$ stretching intensity bond $\left(930 \mathrm{~cm}^{-1}\right)$ than TEOS sample. It is a confirmation for the reduction of $\mathrm{SiOH}$ bonds after treating TEOS sample with hydrolyzed alkyl silane (Hydrolysed OTES ${ }^{32-33}$.

The water-repellent properties of untreated, TEOS-treated, and OTES-TEOS-treated samples are presented in Figure 6. On the untreated sample, the water droplet does not distribute and penetrates the surface in the same place. On the OTES-TEOStreated sample, the water droplet gets distributed on the surface and does not penetrate, because the pores are filled with $\mathrm{SiO}_{2}$ nanoparticles.

The contact angle of water droplets on untreated, TEOS-treated, and OTES-TEOS-treated samples are shown in Figure 6. The water-contact angle on the TEOS-treated sample $\left(76 \pm 0.5^{\circ}\right)$ is lower compared to other samples (Figure 6b \& Table 2). It is because of the presence of hydroxyl groups following the TEOS treatment (Figure 2). Figure $6 c$ shows a spherical-like water droplet with a contact angle of $153 \pm 1.5^{\circ}$ (Table 2). The WSA on the OTES-TEOS-treated sample has decreased to $30^{\circ}$.Thesurface energy of the OTES-TEOS-treated sample is significantly lower than that of the TEOStreated sample due to the presence of hydroxyl groups in the latter.

The surface roughness of a swimsuit or any other moving object submerged in water has an important role in the resultant drag force. In this paper, the drag coefficient $\left(\mathrm{C}_{\mathrm{D}}\right)$ is presented as a function of Reynolds number (Re) (Figure 7). The $\mathrm{C}_{\mathrm{D}}$ and Re were calculated by using the following formulas:

Table 2: Static water, water shedding angles and surface energy of pristine, TEOS and OTES-TEOS-treated samples

\begin{tabular}{lccc}
\hline $\begin{array}{l}\text { Sample kind } / \\
\text { treated with }\end{array}$ & $\begin{array}{c}\text { Mean of static } \\
\text { contact angle } \\
\text { "SWC" }\left(^{\circ}\right)\end{array}$ & $\begin{array}{c}\text { Mean of static } \\
\text { contact angle } \\
\text { "SWC" }\left(^{\circ}\right.\end{array}$ & $\begin{array}{c}\text { Surface } \\
\text { Energy } \\
\mathbf{( N / m})\end{array}$ \\
\hline Pristine & $109 \pm 1.5$ & $109 \pm 1.5$ & $34 \pm 2.7$ \\
TEOS & $76 \pm 0.5$ & $76 \pm 0.5$ & $123 \pm 3.2$ \\
OTES"TEOS & $153 \pm 1.5$ & $153 \pm 1.5$ & $4.5 \pm 0.05$ \\
\hline
\end{tabular}




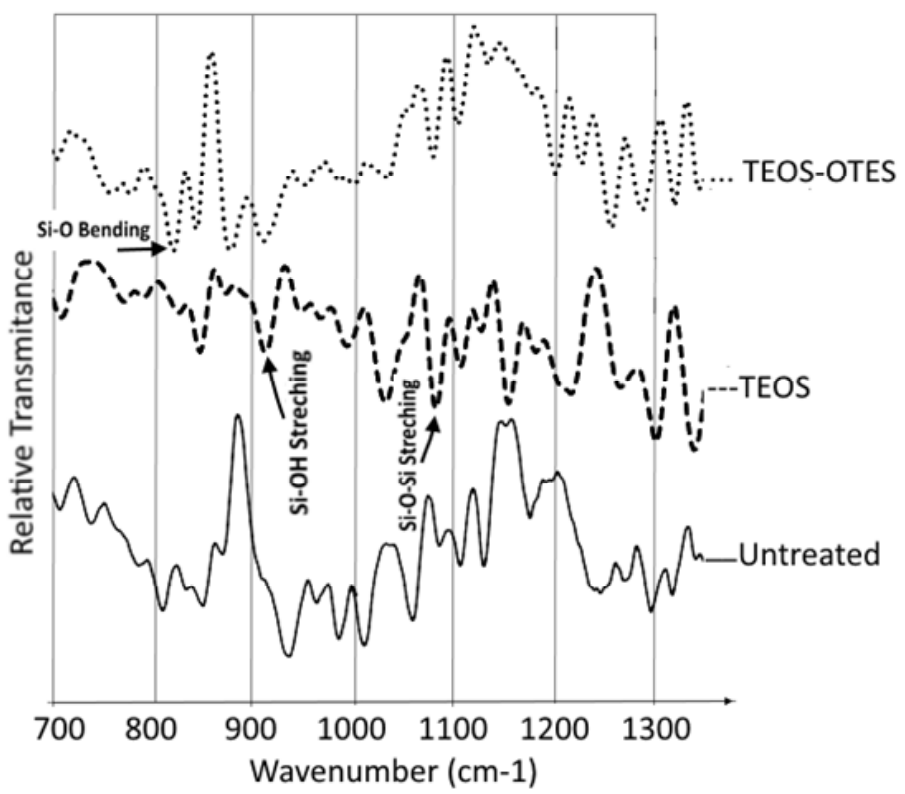

Fig. 5: FTIR of Untreated, TEOS and OTES-TEOS-treated samples
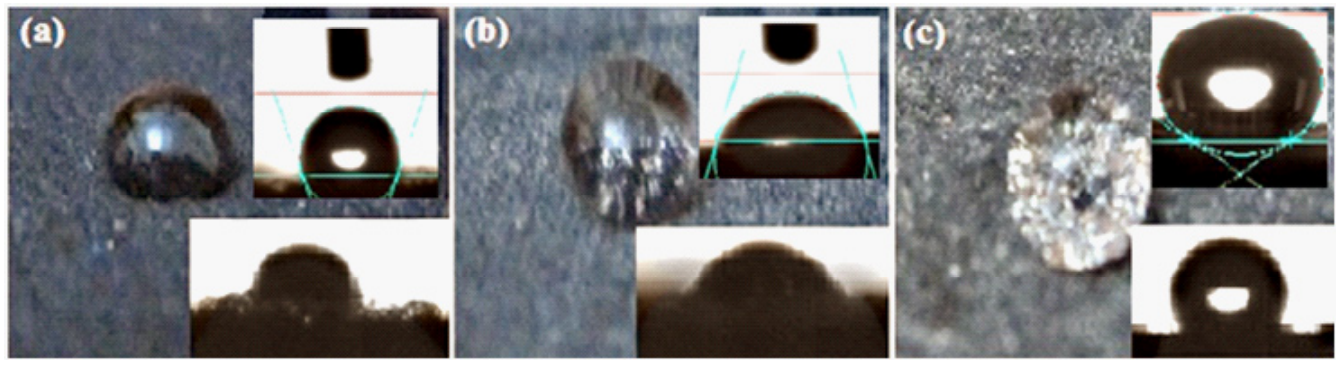

Fig. 6: Contact angles and wettability of (a) Untreated, (b) TEOS and(c) OTES-TEOS-treated samples

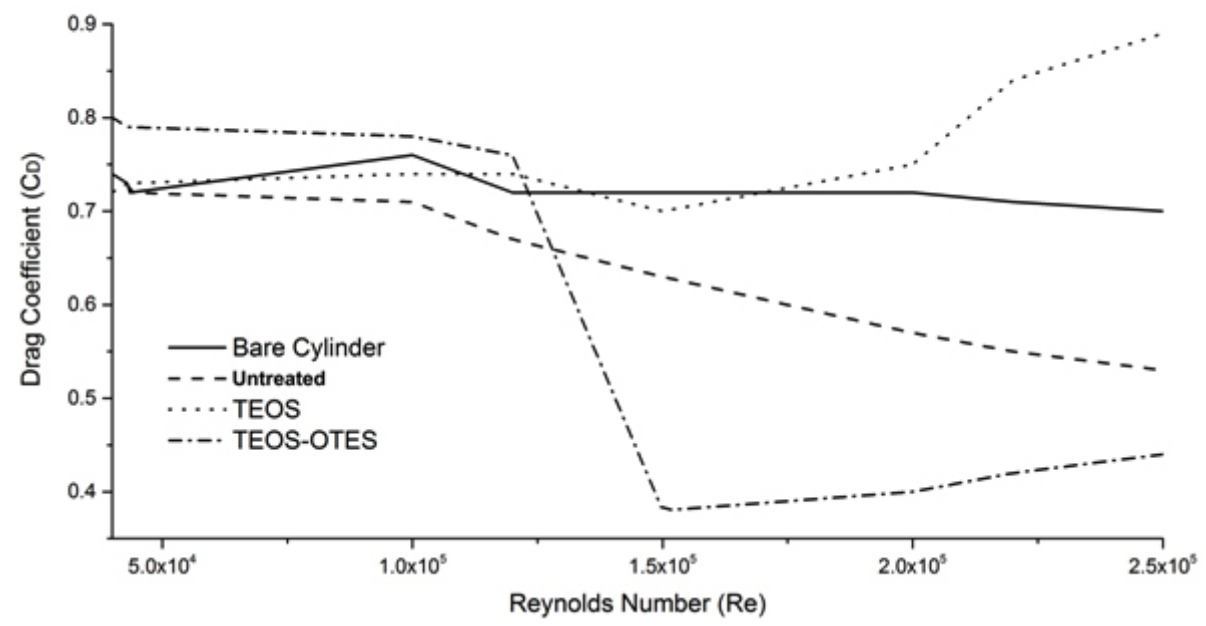

Fig. 7: Drag coefficient values of samples in different Reynolds numbers 
$\mathrm{C}_{\mathrm{D}}=\mathrm{F}_{\mathrm{D}} / 0.5 \rho \mathrm{V}^{2} \mathrm{~A}$

Where $F_{D}$ is drag force, $\rho$ density, $V$ velocity of wind, and $A$ area of samples.

$\mathrm{Re}=\rho \mathrm{VL} / \mu$

Where $\rho, V$ and $\mu$ are density, velocity, and viscosity of wind and $L$ is sample length (Marhino et al., 2012).

For comparison, the $C_{D}$ values of the bare cylinder are also presented in the figure. The surface roughness has a significant effect on the air flow characteristics over the surface.

The data indicates the $C_{D}$ start to decrease for untreated sample at $R e=1.2 \times 10^{5}$. Similarly, the $C_{D}$ of OTES-TEOS samples reduced at $R e=1.5 \times 10^{5}$. It is because of the surface tension decreased by introducing OTES. Moreover, super hydrophobic surfaces contain nanoscale features which cause air trapping and slip. Therefore, the slip leads to drag reduction at higher Reynolds numbers in both laminar and turbulent regimes (Dean \& Bhushan, 2010). In contrast, due to increasing surface tension, the TEOS sample undergoes increase at $\mathrm{Re}=2 \times 10^{5}$.

\section{CONCLUSION}

A commercial wet suit was coated with hydrophobic silica nanoparticles by the sol-gel method. The fabricated layer produced a super hydrphobic layer on the outer layer of the wet suit due to the produced roughness and the low energy of the surface. The wind test results showed the reduction of hydrodynamic drag for the coated wet suitespecially in high Reynolds numbers. It indicates that the super hydrophobic-fabricated layer can act as an air-retaining surface and so the produced air film can reduce the drag due to slip phenomena. The modified wet suit shows high potential for maximizing the mobility of limbs and can be used for distance swimming and triathlon. It can also cooperate with the enclosed bubbled gas of neoprene for improving the insulating ability of such a wet suit.

\section{REFERENCES}

1. Moria, H.;Chowdhury, H.;Alam, F.; Subic, A. Journal of mechanical and industrial engineering.2011, 5, 83-87.

2. Moria, H.;Chowdhury, H.;Alam, F.Procedia Engineering.2011, 13, 389-394.

3. Dean, B.;Bhushan, B. Phil. Trans. R. Soc. A.2010,368, 4775-4806.

4. Marinho, D. A.; Mantha, V. R.; Vilas-Boas, J. P.; Ramos, R. J.; Machado, L.; Rouboa, A. I.; Silva,A. J.Brazilian archives of biology and technology.2012, 55, 851-856.

5. Marinho, D. A.; Mantha, V. R.; Rouboa , A. I.; Vilas-Boas, J. P.; Machado, L.; Barbosa, T. M., Silva, A. J. Port J Sports Sci. 2011, 11, 319-322.

6. Mollendorf, J. C.; Termin, L. A. C.; Oppenheim, E.;Pendergast, D. R. MedSci Sports Exerc. 2004, 36, 1029-1035.

7. Roberts, B. S.; Kamel, K. S.; Hedrick, C.E.; Mclean, Sharp, R. L. Med Sci Sports Exerc. 2003, 35, 519-524.

8. Bhushan, B. Langmuir.2012, 28, 1698"1714.
9. Bixler, G. D.; Bhushan, B.Soft Matter.2012, 8, 11271-11284.

10. Daniello, R. J.; Waterhouse, N. E.; Rothstein, J. P.Physics of fluids. 2009, 085103-1-9.

11. Kim, Y. W.; Lee, J. M.; Lee, I.; Lee, S. H.; Ko, J. S.International journal of precision engineering and manufacturing, 2013, 14, 299-306.

12. Moaven, Kh.; Rad, M.;Taeibi-Rahni, M. Experimental Thermal and Fluid Science.2013, 51, 239-243.

13. Henoch, C., Krupenkin, T., Kolodner, P., Taylor, J., Hodes, M., Lyons, A., Breuer, $K$. Turbulent drag reduction using superhydrophobic surfaces. 3rd AIAA Flow Control Conference.2006.

14. Krupenkin, T. N.; Kolodner, P.; Taylor, J. A.; Hodes, M. S.; Lyons, A. M.; Peguero, C.; Breuer,K. Turbulent Drag Reduction Using Superhydrophobic Surfaces, 3rd AIAA Flow Control Conference 5 - 8 June 2006, San Francisco, California. 
15. Zhang, Y. L.; Xia, H.; Kim, E.; Sun, H. B.Soft Matter, 2012, 8, 11217-1123.

16. Shirtcliffe, N. J.; McHale, G.; Atherton, S.; Newton, M. I.Adv. Colloid Interface Sci.2010, 161, 124-138.

17. Yao, X.; Song, Y.; Jiang, L.Adv. Mater.2011, 23, 719-734.

18. Ionov, L.; Synytska, A.Phys. Chem. Chem. Phys., 2012, 14, 10497-10502.

19. Ma, M.; Mao, Y.; Gupta, M.; Gleason, K. K.; Rutledge, G. C.Macromolecules, 2005,38, 9742-9748.

20. Shi, J.; Alves, N. M.; Mano, J. F.Bioinspiration\&Biomimetics, 2008, 3, 1-6.

21. Han, D.; Steckl, A. J.Langmuir, 2009, 25, 9454-9462.

22. Pozzato, A.; Dal Zilio, S., Fois, G.; Vendramin, D.; Mistura, G.; Belotti, M.; Chen, Y.; Natali,M. Microelectronic Engineering, 2006, 83 (2006), 884-888.

23. Bae, G. Y.; Min, B. G.; Jeong, Y. G.; Lee, S. C.; Jang, J. H.; Koo, G. H.J Colloid Interface Sci.2009, 337, 170-175.

24. Gao, Q.; Zhu, Q.; Guo, Y.Ind. Eng. Chem.
Res.,2009,48 9797-9803.

25. Hao, L. F.; An, Q. F.; Xu, W.; Wang, Q. J.Adv. Mater. Res.2010, 121, 23-26.

26. Li, Z.; Xing, Y.; Dai, J.Appl. Surf. Sci.2008, 254, 2131-2135.

27. Yu, M.; Gu, G.; Meng, W. D.; Qing, F. L.Appl. Surf. Sci.2007, 253, 3669-3673.

28. Xue, C. H.; Jia, S. T.; Zhang, J.;Tian, L. Q.Thin Solid Films. 2009, 517, 4593-4598.

29. Xu, B.; Cai, Z.; Wang, W.; Ge, F.Surf. Coat. Technol.2010, 204, 1556-1561.

30. Brendjchi, A.; Khajavi, R.; Yazdanshenas, M. E. Nanoscale research letters. 2011, 6, 594601.

31. Zimmermann, J.; Seeger, S.; Reifler, F. A. Text. Res. J, 2009, 79, 1565-1570.

32. Bange, J. P.; Patil, L. S.; Gautam, D. K.Progress In Electromagnetics Research M, 2008,3, 165-175, 2008.

33. Shokri, B.; AbbasiFirouzjah, M.; Hosseini, S.FTIR analysis of silicone dioxide thin film deposited by metal organic-based PECVD, International plasma chemistry society (ISPC19), 2009, Bochum, Germany. 